\title{
Pregnancy identity card of women with fetal death in utero: case- control study in a reference hospital in metropolitan Cameroon
}

\author{
Junie Annick Metogo Ntsama ${ }^{1,2}$, Wilfried Loïc Tatsipie ${ }^{1 *}$, Amandine Bayokolak ${ }^{1}$, \\ Veronique Batoum Mboua ${ }^{1,3}$, Chanelle Mbianda ${ }^{1}$, Esther Meka Ngo Um ${ }^{1,4}$, \\ Claude Cyrille Noa Ndoua ${ }^{1,2}$, Pascal Foumane ${ }^{1,4}$
}

\author{
${ }^{1}$ Department of Gynaecology-Obstetrics, Faculty of Medicine and Biomedical Sciences, University of Yaoundé I, \\ Cameroon \\ ${ }^{2}$ Department of Gynaecology-Obstetrics, Yaoundé Hospital Center for Research and Application in Endoscopy Surgery \\ and Human Reproduction, Cameroon \\ ${ }^{3}$ Department of Gynaecology and Obstetrics, Yaoundé Teaching Hospital, Cameroon \\ ${ }^{4}$ Department of Gynaecology-Obstetrics, Yaoundé Gynaeco-Obstetric and Paediatric Hospital, Cameroon
}

Received: 15 January 2022

Accepted: 03 February 2022

\section{*Correspondence:}

Dr. Wilfried loïc Tatsipie,

E-mail: tatsipien@yahoo.fr

Copyright: () the author(s), publisher and licensee Medip Academy. This is an open-access article distributed under the terms of the Creative Commons Attribution Non-Commercial License, which permits unrestricted non-commercial use, distribution, and reproduction in any medium, provided the original work is properly cited.

\begin{abstract}
Background: Intrauterine fetal death is the death of the fetus in the uterus beyond 22 weeks of gestational age and/or weighing $500 \mathrm{~g}$. It is frequent in developing countries, showing that, efforts and progress still need to be made in the follow-up of high-risk pregnancies. The general objective of our study was to identify the associated factors of intrauterine fetal death at the Yaounde gynaeco-obstetric and paediatric hospital.

Methods: We conducted a case-control study at the Yaounde gynaeco-obstetric and pediatric hospital from January 1 April to 30 April 2021. The cases were all women admitted in the service of obstetrics and gynaecology with fetal death from 22 completed weeks of gestation and above confirmed by ultrasound and willing to participate in the study and the controls were any women admitted in the service who gave birth to a live fetus and willing to participate with maternal age as the matching criteria. We recruited 42 cases for 84 controls making one case for two controls. The statistical analysis was done using SPSS software version 23.0 and excel 2016.

Results: The associated factors for intrauterine fetal death found during our study were: being single $(\mathrm{ORa}=3,6 ; \mathrm{CI}=$ 1.3-1.9), less than four antenatal consultations $(\mathrm{ORa}=3.6 ; \mathrm{CI}=1.3-10.1)$ and being followed by a midwife $(\mathrm{ORa}=6.6$; $\mathrm{CI}=1.0-41.7)$.

Conclusions: The elements of the identity card of a pregnant woman with fetal death in utero are: being single, less than four antenatal consultations and being followed by a midwife.
\end{abstract}

Keywords: Intra uterine fetal death, Associated factors, Cameroon

\section{INTRODUCTION}

Fetal death in utero (FIDU) is defined by the world health organization (WHO) as the death of an in-utero fetus beyond 22 weeks of amenorrhea or weighing at least $500 \mathrm{~g}$. Since the 2014 recommendations, the Collège
National des gynécologues at obstétriciens français (CNGOF) has adopted a broader definition by including all in-utero deaths beyond 14 weeks of amenorrhea. ${ }^{1}$ In utero fetal death is a serious event with a prevalence of $2 \%$ worldwide per year of which $98.0 \%$ of cases are in developing countries. The frequency of fetal death varies 
from one country to another depending on the socioeconomic standard of living and the quality of pregnancy management. In Europe, the 2014 study by Delabaerea et al covering 24 countries found a rate of in utero fetal death ranging from 0.17 to $0.49 \%$ of births. ${ }^{2}$ In Africa, the available data are variable: in 2018 a study showed a prevalence of $3.69 \%$ in Equatorial Guinea, $13.98 \%$ in Congo in 2016; $5.22 \%$ in Madagascar in 2013.3.5 In Cameroon a study done by Nkwabong et al at the Yaounde university hospital centre showed in 2012 a rate of fetal death in utero at $3.40 \%{ }^{6}$ High rates in Africa compared to Europe shows how much progress and effort still needs to be done in monitoring pregnancies, especially those at risk. Several risk factors have been identified and the most frequent are: obesity, maternal age over 35 years, smoking, hypertension during pregnancy. ${ }^{7}$ The etiologies found were: funicular anomalies, maternal haemorrhage, chromosomal and malformations, infections. ${ }^{7}$ The diagnosis confirmatory is made by ultrasound and the etiological diagnosis may require specific examinations such as fetal autopsy, placenta analysis, fetal karyotype. ${ }^{7}$ Fetal death in utero is responsible for several complications that may jeopardize the maternal vital prognosis. These complications are mainly haemorrhagic by disseminated intravascular coagulation (DIC) and retention of placental debris, infectious (chorioamniotitis) and especially psychological. $^{8}$ The psychological consequences will most often have repercussions on subsequent pregnancies. It is therefore urgent and important for the medical team to develop a preventive health policy for fetal death in utero, by identifying the risk factors and etiologies in order to reduce the rate of fetal death in utero. Since the rates are high in Africa, we wanted to assess the extent of the problem in a referral hospital specializing in the health of the mother and child. The general objective of this study was to study the factors associated with fetal death in utero in order to contribute to the improvement of the well-being of the mother and child in Yaoundé.

\section{METHODS}

\section{Setting, type and period of study}

This was a case-control study conducted in gynecologyobstetrics department of the Yaoundé Gyneco-Obstetrics and pediatrics hospital from 1 January to 30 April, 2021.

\section{Study population and sample size}

This study concerned all pregnant women admitted to the gynaecological-obstetric and paediatric hospital of Yaoundé during the period of our research for fetal death in utero. The latter were compared to a group of controls from the same health structure and the same period with maternal age as a matching criterion. Each case of in utero fetal death was matched with two controls. Thus, 42 cases were matched to 84 controls.

\section{Inclusion and exclusion criteria}

The study included cases of in utero fetal deaths and their controls selected according to the selection criteria described below, and excluded cases of intrapartum death, therapeutic termination of pregnancy, voluntary termination of pregnancy, death before viability, or any woman who withdrew her consent.

\section{Definition of cases and controls}

Case: woman admitted in the gynecology and obstetrics department for ultrasound confirmed in utero fetal death beyond 22 weeks of amenorrhea and consenting to participate in the study. Controls: women admitted to the gynecology and obstetrics department who delivered a live fetus and who consented to participate in the study

\section{Data collection and statistical analysis}

Socio-demographic, clinical and therapeutic data were collected on a pre-established data collection form submitted to the women concerned. The data were entered and analyzed using the Statistical Package of Social Sciences (SPSS) software version 23.0. Microsoft Excel and Word application software were used for data processing. Chi-square test was used to measure the association between categorical variables. Then a univariate analysis followed by a multivariate analysis was done using the multinomial logistic regression method to search for the factors associated with fetal death. The confidence interval was $95 \%$. When the $\mathrm{P}$ value was less than 0.05 , the result was considered statistically significant.

\section{RESULTS}

Single women were 4.9 times more likely to have an in utero fetal death. There was no association between region of origin, place of residence, occupation, education level of the patients and the occurrence of in utero fetal death. Nulliparity and previous in utero fetal death were associated with the occurrence of in utero fetal death and increased the risk of its occurrence by 2.1 (CI: 1.0-4.5) and 3.4 (CI: 1.2-9.8) respectively. Women with fewer than four antenatal contacts, fewer than three doses of intermittent preventive treatment for malaria, and those attended by midwives had 3.7 (CI: 1.5-8.8), 2.5 (CI: 1.2-5.4), and 5.5 (CI 1.0-29.8) times the risk of in utero fetal death respectively. Regarding fetal characteristics, sex and presentation were not related to the occurrence of in utero fetal death, but male sex was the most represented with a percentage of $59.5 \%$ and $79.1 \%$ of cases were born in cephalic presentation. Prematurity multiplied the risk of in utero fetal death by 7.8 (CI: 3.3-17.8). A weight of less than $2500 \mathrm{~g}$ was associated with in utero fetal death with a risk multiplied by 6.7 (CI: $3.0-15.2)$. 
Table 1: Socio-demographic characteristics.

\begin{tabular}{|c|c|c|c|c|}
\hline Variables & $\begin{array}{l}\text { Case } \\
\mathrm{N}=42 \\
\text { Frequency }(\%)\end{array}$ & $\begin{array}{l}\text { Witnesses } \\
\mathbf{N}=\mathbf{8 4} \\
\text { Frequency }(\%)\end{array}$ & OR $(95 \% \mathrm{CI})$ & P value \\
\hline \multicolumn{5}{|l|}{ Age groups (years) } \\
\hline $15-20$ & $1(2.4)$ & $6(7.1)$ & $0.3(0.0-2.7)$ & 0.256 \\
\hline $20-25$ & $10(23.8)$ & $15(17.9)$ & $1.4(0.6-3.5)$ & 0.287 \\
\hline $25-30$ & $14(33.3)$ & $19(22.6)$ & $1.7(0.7-3.9)$ & 0.142 \\
\hline $30-35$ & $9(21.4)$ & $25(29.8)$ & $0.6(0.3-1.5)$ & 0.219 \\
\hline $35-40$ & $5(11.9)$ & $13(15.5)$ & $0.7(0.2-2.2)$ & 0.402 \\
\hline $40-45$ & $3(7.1)$ & $6(7.1)$ & $1.0(0.2-4.2)$ & 0.654 \\
\hline \multicolumn{5}{|l|}{ Marital status } \\
\hline Single & $36(85.7)$ & $46(54.8)$ & $4.9(1.9-13.0)$ & \multirow{2}{*}{0.001} \\
\hline Married & $6(14.3)$ & $38(45.2)$ & - & \\
\hline \multicolumn{5}{|l|}{ Place of residence } \\
\hline Urban & $31(73.8)$ & $69(82.1)$ & $0.6(0.3-1.5)$ & 0.195 \\
\hline \multicolumn{5}{|l|}{ Region of origin } \\
\hline Adamaoua & $0(0)$ & $1(1.2)$ & $1.5(1.3-1.7)$ & 0.667 \\
\hline Center & 15 (35.7) & 24 (28.6) & $1.4(0.6-3.1)$ & 0.268 \\
\hline East & $1(2.4)$ & $1(1.2)$ & $2.0(0.1-33.2)$ & 0.557 \\
\hline Far North & $0(0)$ & $4(4.8)$ & $1.5(1.3-1.7)$ & 0.193 \\
\hline Coastal & $6(14.3)$ & $6(7.1)$ & $2.2(0.6-7.2)$ & 0.166 \\
\hline North & 0 & $3(3.6)$ & $1.5(1.3-1.7)$ & 0.293 \\
\hline West & $15(35.7)$ & $34(40.5)$ & $0.8(0.4-1.7)$ & 0.375 \\
\hline Northwest & $2(4.8)$ & $9(10.7)$ & $0.4(0.9-2.0)$ & 0.222 \\
\hline South & $3(7.1)$ & $1(1.2)$ & $6.4(0.6-63.4)$ & 0.108 \\
\hline Foreign & $0(0.0)$ & $1(1.2)$ & $1.5(1.3-1.7)$ & 0.667 \\
\hline \multicolumn{5}{|l|}{ Profession } \\
\hline Housekeeper & $9(21.4)$ & $21(25.0)$ & $0.8(0.3-2.0)$ & 0.417 \\
\hline Public sector employee & $4(9.5)$ & $17(20.2)$ & $0.4(0.1-1.3)$ & 0.100 \\
\hline Private sector employee & $6(14.3)$ & $6(7.1)$ & $2.2(0.7-7.2)$ & 0.166 \\
\hline Informal sector employee & $12(28.6)$ & $26(31.0)$ & $0.9(0.4-2.0)$ & 0.476 \\
\hline Pupil/student & $11(26.2)$ & $14(16.7)$ & $1.8(0.7-4.3)$ & 0.152 \\
\hline \multicolumn{5}{|l|}{ Level of study } \\
\hline Illiterate & 0 & $4(4.8)$ & $1.5(1.3-1.7)$ & 0.193 \\
\hline Primary & $10(23.8)$ & $10(11.9)$ & $2.3(0.9-6.1)$ & 0.074 \\
\hline Secondary & $12(28.6)$ & $32(38.1)$ & $0.6(0.3-1.4)$ & 0.196 \\
\hline Superior & $20(47.6)$ & $38(45.2)$ & $1.1(0.5-2.3)$ & 0.474 \\
\hline
\end{tabular}

In multivariate analysis, the independent factors associated with in utero fetal death were single status, fewer than four prenatal visits, and midwives as providers of prenatal visits $(\mathrm{p}<0.05)$.

\section{DISCUSSION}

\section{Socio-demographic characteristics}

Age: we found that pregnant women with in utero fetal death had an age range between 15 and 44 years. This age is comparable to the 15 to 45 years found by Diallo et al in 2015 at the regional hospital of Mamou. ${ }^{9}$ In our study, the age range of 25 to 30 years was the most represented (29.5\%) but was not associated with the occurrence of fetal death in utero. This can be explained by the fact that this is the reproductive age.

Educational level: in our study, we found a predominance secondary and higher educational level (80.9\%) unlike Kangulu et al in 2016 who found a primary level in majority. ${ }^{4}$ This can be explained by the fact that our patients live in the city and had the opportunity to be educated.

Place of residence: rural residence was also identified as an associated factor by Kangulu et al in 2016 with 3.7 times more risk of in utero fetal death unlike our study which showed that majority of the patients resided in urban area (79.4\%) and this was not associated with in utero fetal death. ${ }^{4}$ 
Table 2: Clinical characteristics of patients.

\begin{tabular}{|c|c|c|c|c|}
\hline \multirow[b]{2}{*}{ Variables } & \multirow{2}{*}{$\begin{array}{l}\text { Case } \\
\mathrm{N}=42 \\
\text { Frequency }(\%)\end{array}$} & \multirow{2}{*}{$\begin{array}{l}\text { Witnesses } \\
\mathbf{N}=\mathbf{8 4} \\
\text { Frequency }(\%)\end{array}$} & \multirow[b]{2}{*}{ OR $(95 \% \mathrm{CI})$} & \multirow[b]{2}{*}{$P$ value } \\
\hline & & & & \\
\hline \multicolumn{5}{|l|}{ Body mass index } \\
\hline Underweight & 0 & $2(2,4)$ & $1,5(1,3-1,7)$ & 0,443 \\
\hline Normal & $10(23.8)$ & $29(34.5)$ & $0.6(0.3-1.4)$ & 0.153 \\
\hline Overweight/Obesity & $32(76.2)$ & $53(63.1)$ & $1.9(0.8-4.3)$ & 0.100 \\
\hline \multicolumn{5}{|l|}{ Gravida } \\
\hline Primigravida (G1) & $12(28.6)$ & $17(20.2)$ & $1.6(0.7-3.7)$ & 0.204 \\
\hline Primate-Pauciparous (G2-G4) & $16(38.1)$ & $41(48.8)$ & $0.6(0.3-1.4)$ & 0.171 \\
\hline Paucigravida-Multigravida (G5-G6) & $9(21.4)$ & $18(21.4)$ & $1.0(0.4-2.4)$ & 0.596 \\
\hline Multigravida (G7) & $5(11.9)$ & $8(9.5)$ & $1.3(0.4-4.2)$ & 0.448 \\
\hline \multicolumn{5}{|l|}{ Parity } \\
\hline Nulliparous (P0) & $20(42.9)$ & $25(28.6)$ & $2.1(1.0-4.5)$ & 0.040 \\
\hline Primaparous $(\mathrm{P} 1)$ & $9(21.4)$ & $20(23.8)$ & $0.9(0.4-2.1)$ & 0.476 \\
\hline Pauciparous (P2-P4) & $9(23.8)$ & $30(35.7)$ & $0.6(0.2-1.3)$ & 0.124 \\
\hline Multiparous (P4-P6) & $2(7.1)$ & $7(8.3)$ & $0.8(0.2-3.4)$ & 0.559 \\
\hline Large multiparous (P7) & $2(4.8)$ & $2(3.6)$ & $1.3(0.2-8.4)$ & 0.559 \\
\hline History of fetal death in utero & $10(23.8)$ & $7(8.3)$ & $3.4(1.2-9.8)$ & 0.019 \\
\hline History of abortion & $14(33.3)$ & $25(29.8)$ & $1.2(0.5-2.6)$ & 0.416 \\
\hline History of caesarean section & $2(4.8)$ & $10(11.9)$ & $0.4(0.8-1.8)$ & 0.163 \\
\hline \multicolumn{5}{|l|}{ Nature of the pregnancy } \\
\hline Singleton & $39(92.9)$ & $79(94.0)$ & $0.8(0.2-3.6)$ & 0.535 \\
\hline Multiple & $3(7.1)$ & $5(6.0)$ & - & - \\
\hline \multicolumn{5}{|l|}{ Number of ANC performed } \\
\hline$<4$ & $16(38.1)$ & $12(14.3)$ & $3.7(1.5-8.8)$ & 0.003 \\
\hline$\geq 4$ & $26(61.9)$ & $72(85.7)$ & - & - \\
\hline First NPC in the first quarter & $17(40.5)$ & $43(51.2)$ & $0.6(0.3-1.4)$ & 0.172 \\
\hline \multicolumn{5}{|l|}{ ANC provider } \\
\hline Gynecologist-obstetrician & $19(45.2)$ & $49(58.3)$ & $0.6(0.3-1.2)$ & 0.115 \\
\hline General practitioner & $2(4.8)$ & $8(9.5)$ & $0.4(0.1-2.3)$ & 0.289 \\
\hline Midwife & $5(11.9)$ & $2(2.4)$ & $5.5(1.0-29.8)$ & 0.041 \\
\hline Nurse & $16(38.1)$ & $25(29.8)$ & $1.4(0.7-3.1)$ & 0.229 \\
\hline Iron / folic acid supplementation & $38(92.7)$ & $72(85.7)$ & $2.1(0.6-7.9)$ & 0.205 \\
\hline Use of LLINs & $36(87.8)$ & $76(90.5)$ & $0.8(0.2-2.5)$ & 0.430 \\
\hline \multicolumn{5}{|l|}{ Number of IPTs } \\
\hline$<3$ doses & $24(58.5)$ & $30(36.1)$ & $2.5(1.2-5.4)$ & 0.015 \\
\hline$\geq 3$ doses & $17(41.5)$ & $53(63.9)$ & - & - \\
\hline
\end{tabular}

$\mathrm{ANC}=$ antenatal consultation, IPT $=$ intermittent preventive treatment, LLIN $=$ long-lasting insecticidal net

\section{Factors associated with in utero fetal death}

Marital status: single women were the most affected in our series $(85.7 \%)$ which is comparable to the study conducted in Guinea in 2018 by Soumah et al who found $79.3 \%$ of single women in their population. ${ }^{3}$ We found during our study that unmarried women were 4.9 times more likely to have a fetal death in utero. This phenomenon could be explained by the fact that they were carrying an unwanted pregnancy and found themselves without any financial assistance due to the abandonment of the parents and/or the genitor, and were therefore unable to carry out their prenatal follow-up correctly.

History of fetal death in utero: a history of fetal death in utero is a significant associated factor of fetal death in utero. These results were confirmed in two meta-analyses by Flenady including five studies and finding a 2.6-fold increase in the risk of death in subsequent pregnancies $(95 \%$ CI $1.5-4.5) .^{10}$ 
Table 3: Population distribution by fetal characteristics.

\begin{tabular}{|c|c|c|c|c|}
\hline Variables & $\begin{array}{l}\text { Case } \\
\mathrm{N}=42 \\
\text { Frequency (\%) }\end{array}$ & $\begin{array}{l}\text { Witnesses } \\
\text { N=84 } \\
\text { Frequency (\%) }\end{array}$ & OR $(95 \% \mathrm{CI})$ & $P$ value \\
\hline \multicolumn{5}{|l|}{ Sex } \\
\hline Male & $25(59.5)$ & $50(59.5)$ & $1.0(0.5-2.1)$ & 0.575 \\
\hline Female & $17(40.5)$ & $34(40.5)$ & $1.3(0.6-2.8)$ & 0.284 \\
\hline \multicolumn{5}{|l|}{ Gestational age } \\
\hline $22-37 \mathrm{SA}$ & $29(69.0)$ & $18(20.9)$ & $7.8(3.4-17.8)$ & \multirow{2}{*}{0.020} \\
\hline $37-42$ SA & $13(31.0)$ & $66(79.1)$ & $0.1(0.1-0.3)$ & \\
\hline \multicolumn{5}{|l|}{ Presentation } \\
\hline Cephalic & $34(79.1)$ & $74(88.1)$ & $0.6(0.2-1.5)$ & 0.303 \\
\hline Headquarters & $7(16.7)$ & $9(10.7)$ & $1.9(0.7-5.4)$ & 0.162 \\
\hline Transverse breech & $1(2.4)$ & $1(1.2)$ & $1.0(0.1-11.2)$ & 0.739 \\
\hline \multicolumn{5}{|l|}{ Weight (g) } \\
\hline$<2500$ & $26(61.9)$ & $15(17.9)$ & $6.7(3.0-15.2)$ & \multirow{2}{*}{0.031} \\
\hline$>2500$ & $16(38.1)$ & $69(82.1)$ & $0.2(0.1-0.3)$ & \\
\hline
\end{tabular}

Table 4: Multivariate analysis.

\begin{tabular}{|c|c|c|c|c|}
\hline \multirow[b]{2}{*}{ Variables } & \multirow{2}{*}{$\begin{array}{l}\text { Case } \\
\mathrm{N}=42 \\
\text { Frequency }(\%)\end{array}$} & Witnesses & \multirow[b]{2}{*}{ OR $(95 \% \mathrm{CI})$} & \multirow[b]{2}{*}{ P value } \\
\hline & & $\begin{array}{l}\mathrm{N}=84 \\
\text { Frequency (\%) }\end{array}$ & & \\
\hline \multicolumn{5}{|l|}{ Marital status } \\
\hline Single & $36(85.7)$ & $46(54.8)$ & $3.6(1.3-9.9)$ & 0.015 \\
\hline History of fetal death in utero & $10(23.8)$ & $7(8.3)$ & $3.0(0.9-9.7)$ & 0.070 \\
\hline \multicolumn{5}{|l|}{ Number of ANC performed } \\
\hline$<4$ & $16(38.1)$ & $12(14.3)$ & $3.6(1.3-10.1)$ & 0.013 \\
\hline \multicolumn{5}{|l|}{ ANC provider } \\
\hline Midwife & $5(11.9)$ & $2(2.4)$ & $6.6(1.0-41.7)$ & 0.045 \\
\hline \multicolumn{5}{|l|}{ Number of IPTs } \\
\hline$<3$ doses & $24(58.5)$ & $30(36.1)$ & $1.4(0.6-3.7)$ & 0.415 \\
\hline Nulliparity & $20(42.9)$ & $25(28.6)$ & $1.7(0.7-4.2)$ & 0.252 \\
\hline Gestational age $<37 \mathrm{SA}$ & $29(69.0)$ & $18(20.9)$ & $5.2(2.1-13.1)$ & 0.061 \\
\hline Fetal weight $<2500 \mathrm{~g}$ & $26(61.9)$ & $15(17.9)$ & $4.8(1.9-9.8)$ & 0.072 \\
\hline
\end{tabular}

Our study found that a history of fetal death in utero multiplies the risk of fetal death in the next pregnancy by $3.4(1.2-9.8)$ with a significant $\mathrm{p}$ value of 0.019 .

Parity: we found nulliparity as a factor associated with in utero fetal death which multiplied the risk by 2.1 . Flénady et al showed that there was an increased risk of fetal death of 1.42 (95\% CI 1.33-1.51). ${ }^{10}$ These patients represent a population more exposed to certain pathologies such as pre-eclampsia which is a cause of fetal death in utero.

Pregnancy monitoring: Poor pregnancy monitoring increases the risk of in utero fetal death.,11 The new recommendations of the world health organization state that at least eight good quality prenatal visits should be made. Pregnancy follow-up should be done by a gynecologist, intermittent preventive treatment should be taken every month from sixteen weeks of amenorrhea with at least three doses. In our context, these new recommendations are not yet really applied and we still consider the four refocused consultations. This justifies the fact that we have had fewer than four prenatal consultations and less than three doses of intermittent malaria treatment and being followed by a midwife who is not suitable for consultation as a factor associated with fetal death in utero.

Fetal characteristics: our study was able to establish an association between prematurity and fetal death in utero. Prematurity was associated with fetal death in utero in $69.0 \%$ of cases. This result is comparable to that found by Andriamandimbison et al in Madagascar in 2013, who showed that fetal death in utero was associated with prematurity in $64.4 \%$ of cases. ${ }^{5}$ This is due to the fact that when fetal death is diagnosed the delivery was done at that gestational age. Fetal weight was associated with in utero fetal death when the weight was less than $2500 \mathrm{~g}$ 
and increased the risk by 6.7 times. Tensay et al in 2017 in his study on determinants of in utero fetal death found that fetuses with weight less than $2500 \mathrm{~g}$ died more compared to those with weight more than $2500 \mathrm{~g}$ $\left(\mathrm{OR}=0.27\right.$, 95\% CI: 0.14-0.53). ${ }^{12}$ Our results can be explained by the fact that the weight depends on the gestational age and the majority of our cases of fetal death in utero were premature babies who could not reach the normal weight of a full term fetus which is $2500 \mathrm{~g}$ and also the occurrence of hypertensive pathology which can cause fetal suffering and impede fetal growth.

\section{Limitations}

Limitation of current study was the inability to verify the veracity of information derived from the interview.

\section{CONCLUSION}

This study was conducted to investigate the factors associated with fetal death in utero at the Yaounde gynaeco-obstetric and paediatric hospital. It was found that the associated factors are: celibacy, less than four prenatal contacts and follow-up by a midwife. Any pregnant woman presenting these factors must benefit from a closer follow-up by respecting the schedule of prenatal consultations as recommended by WHO and be followed by a gynaecologist or a better trained midwife.

Funding: No funding sources

Conflict of interest: None declared

Ethical approval: The study was approved by the Institutional Ethics Committee

\section{REFERENCES}

1. Lansac J, Descamps P, Oury J. Pratique de l'accouchement. 5théd. Paris: Masson; 2011:593.

2. Delabaerea A, Huchonc C, Deffieuxe, Beucherf, Gallote V, Nedellece S, et al. Epidemiology of loss pregnancy. J Gynecol Obstet et Biol de la Reprod. 2014;43:764-75.

3. Soumah AF, Tseunwo T, Bah O, Tebeu P, Sy T. Epidemiological profile and management modalities of pregnant women with in utero fetal death before labor in a level II maternity hospital in Guinea. Health Sci Dis. 2018;19(1).
4. Ignace B K, Albert M T, Ngoy L, Kilolo NE, Kabamba NM, Kalenga MK. Maternal frequency and risk factors for in utero fetal death in Kamina, Democratic Republic of Congo. PAMJ. 2016;23:114.

5. Andriamandimbison Z, Randriambololona D, Rasoanandrianina BS, Hery RA. Aetiologies of fetal death in utero: about 225 cases at Befelatanana Hospital Madagascar. Trop Med Health. 2013;23:7882.

6. Nkwabong E, Fomulu JN, Ambassa JL. Stillbirths at University Teaching Hospital, Yaoundé, Cameroon. Int J Gynaecol Obstet. 2012;119(1):87-8

7. Quibel T, Bultez T, Nizard J, Subtil. Fetal deaths in utero. J Gynecol Obstet Bbio Reprod.2014;43:883907.

8. Cabrol D, Pons JC, Goffinet F. Mort fœtale in utero. Traité d'Obstétrique de paris: Med Sci Flam. 2003: 353-8.

9. Diallo MH, Baldé IS, Diallo O, Diallo BS, Baldé A, Barry H, Baldé M D, Keita N. Fetal death in utero (FIDU): Sociodemographic aspect, management and maternal prognosis at the maternity ward of Mamou regional hospital. Rev Int Sci Med. 2016;18(3):231034.

10. Flenady V, Koopmans L, Middleton P, Frøen JF, Smith GC, Gibbons K, et al. Major risk factors for stillbirth in high-income countries: A systematic review and meta-analysis. Lancet. 2011;377(9774): 1331-40.

11. Traore' Y, Teguete' I, Thera AT. Socio-demographic aspects and prognosis of unattended pregnancies in patients admitted to the gynecology-obstetrics department of Gabriel Toure Hospital. Mali Med. 2007;22:39-43.

12. Tensay K., Tegene L. Dadi and Kebadnew M. Determinants of stillbirth in Bonga General and Mizan Tepi University Teaching Hospitals southwestern Ethiopia, 2016: a case-control study. BMC Res Notes. 2017;10:713.

Cite this article as: Ntsama JAM, Tatsipie WL, Bayokolak A, Mboua VB, Mbianda C, Um EMN, et al. Pregnancy identity card of women with fetal death in utero: case-control study in a reference hospital in metropolitan Cameroon. Int J Reprod Contracept Obstet Gynecol 2022;11:683-8. 